\title{
Two Psychologically Based Conflict Resolution Programs: Enemy I mages and US \& THEM
}

\author{
Stephen D. Fabick, Ed. D.
}

\begin{abstract}
Psychologists for Social Responsibility (PsySR) is an international network of professionals who use psychological research and skills to promote peace. Two programs have been developed by PsySR members to help achieve this goal. In 1989 PsySR developed a program aimed at reducing the threat of nuclear war between the two super powers. After the end of the Cold War, PsySR members developed another program that focused on smaller group conflict reduction. Since $9 / 11$, both programs have been updated.
\end{abstract}

Keywords: Psychologists for Social Responsibility, Enemy Images, US \& Them

We don't see things as they are; we see things as we are.

Anais Nin

This article will focus on the development of two psychologically based programs aimed at reducing conflict. Both have evolved into a second edition post 9/11 in order to address the specific challenges in moderating global tensions subsequently.

\section{Ovenview of the Two Enemy I mages Project}

The first of these programs, the Enemy Images program, was developed by a number of members of Psychologists for Social Responsibility in order to deal with the escalation of nuclear arsenals in the United States and in the former Soviet Union. That Manual was titled Dismantling the Mask of Enmity: An Educational Resource Manual on the Psychology of Enemy Images and was published in 1989. It quickly became known simply as "the Enemy Images Manual."

The post 9/11 edition of it is titled Enemy Images: A Resource Manual on Reducing Enmity. It was published in 2004 and edited by Stephen Fabick for Psychologists for Social Responsibility. 
Like its predecessor, it examines the psychological processes involved in making people into enemies. Its focus is the new East/West conflict of Western Imperialism vs. Islamic Terrorism.

Enemy imaging is described as "the psychological fuel for war" and is typically characterized by distorted representations of one's adversary. Often enemies are depicted as thoroughly diabolical, aggressive, and untrustworthy. Exaggerated representations of adversaries are generated at the preconscious level in all of us through selective attention and memory, double standards, self-fulfilling prophecies, and ignorance. The Enemy Images manuals cite historical, media, and research examples of these mechanisms. Sample lectures are included in the respective manuals, as well as a variety of exercises that behavioral scientists can use to moderate such unconscious and regressive thinking. They can be used in a classroom or workshop setting.

\section{Development and History of the Enemy I mages Manuals}

Members of Psychologists for Social Responsibility (PsySR) began working on the issue of enemy images in 1984. "To create an Enemy", a poem by Sam Keen, was reprinted in the PsySR Winter newsletter that year. An article on "The Enemy Image" by Brett Silverstein of City College of New York appeared in the Fall 1985 newsletter, culminating in the New York PsySR chapter sponsoring a conference on "Psychology of the Enemy Image" on January 31, 1987, at John J ay College of Criminal J ustice, NYC, that was attended by 110 people.

Afterwards, work on the Enemy Image project intensified, with Silverstein coordinating the effort. Around that time, Brett co-edited an issue of the Journal of Social Issues (Holt and Silverstein, 1989) devoted to research on the psychology of enemy images. Others who worked on the project included Mike Wessells, Linden Nelson, Dorothy Ciarlo, Susan McKay, Ralph White and Brewster Smith. PsySR Coordinator, Anne Anderson, was also instrumental in the development of the project. Two PsySR supported symposia focused on enemy images search at the American Psychological Association convention in 1989.

After the Convention, PsySR members began making presentations on enemy images around the country and speaker packets were sent to 100 psychologists around the country the following year. Sandra McPherson piloted the project in her home stateof Ohio. Enemy Images presentations were conducted at universities, service clubs, and community groups. The Enemy Images packet was revised based upon the experience of early presenters and contributors. Then the first real Manual was written and disseminated around the country to PsySR members in 1989. It was titled Dismantling the Mask of Enmity: An Educational Resource Manual on the Psychology of Enemy Images, or as mentioned earlier "the Enemy Images manual." That title was used by Brett Silverstein (1989) for his article "Enemy Images: the Psychology of U.S. Attitudes and Cognitions Regarding the Soviet Union" which appeared in the American Psychologist.

The Enemy Images Resource Manual applied psychological research to the overarching problem of the day, nuclear proliferation. It highlighted the role that psychological issues play in war and explained the process of "enemy imaging", i.e. exaggerating the negative aspects of an adversary to the point of seeing them as thoroughly aggressive, untrustworthy, and diabolical. Enemy I mages were described as the psychological fuel of the arms race. 
Borrowing from social psychology research, the Enemy Images materials clarified large group processes that can lead to what has since been termed "enmification" by Reiber and Kelley (1991), as the "psychological and social factors and their concomitants that go into the process of enemy-making". The term refers to the psychological factors leading to imaging the enemy in a way that leads to enemy-making. Such enmification develops through the psychological processes of stereotyping, selective perception (Silverstein and Flamenbaum, 1989), mirrorimaging of the enemy (Bronfenbrenner, 1961), dehumanization, biased attributions (Oskamp, 1965), attribution errors (Taylor and Jaggi, 1974; Sande et al, 1989), and thepsychological need to have an enemy (Volkan, 1988; Middents, 1990).

The program required clinical skills in the presenter in order to foster participant's realistic empathy, critical thinking, experiential learning, and dialogue ability. The experiential aspect of the Enemy Images project was emphasized to increase the chance that program participants might experience some attitude change. The Manual provided a variety of exercises that allowed for flexibility in tailoring presentations according to the allotted time and audience characteristics.

The Enemy Images Manual was a tangible contribution to other organizations and professionals. It provided an ongoing, proactive program while PsySR addressed a variety of other challenges in a more reactive and nimble fashion.

\section{Détente: The Need for an Updated Program-The first US \& THEM Program}

The dismantling of the Berlin Wall in 1989 signaled the end of the Cold War. And at that point the Enemy Images project, with nuclear threat as its focus, became somewhat obsolete. Most of the examples in the program were based upon Soviet-U.S. enmity and the arms build-up, especially nuclear proliferation. Additionally, the fall of the Berlin Wall heralded the beginning of ethnicity as the primary organizing entity of group relations and conflicts around the world. In an unpublished paper at the time, Itzkowitz and Volkan contended that “...nationalism's day may now have passed; after the retreat of the European empires and the collapse of the Soviet Union, we may very well be living in an 'Age of Ethnicity."' They cited the emergence of tribal warfare in Africa, ethnic strife in the former Yugoslavia, Sunni and Shiite strife, and conflicts in Cyprus and in Sri Lanka in the early 1990's.

The Michigan chapter of PsySR began focusing on such conflicts in 1993 with the goal of developing a program to help moderate them. Clearly, the Enemy I mages program would need a major overhaul to be a useful tool in dealing with this shift in international tensions. So members of the Michigan chapter focused upon the work on group prejudice and conflict reduction (Hunt, 1991; Kats, 1982; Stein, 1980). But one book was particularly applicable to the new paradigm of international relations and tensions: US and THEM: The Psychology of Ethnonationalism (1987). It provided a conceptual basis for months of study and discussion among chapter members. They began doing local talks and workshops on a presentation titled US \& THEM: The Challenge of Diversity. The program's purpose was to help participants understand and moderate their prejudice and risk of conflict with members of another group. 


\section{Overview of the US \& THEM: The Challenge of Diversity Program}

In 1996 US \& THEM: The Challenge of Diversity Presenter's Manual (Fabick) was written. As was the case with the Enemy Images Resource Manual, the US \& THEM Presenter's Manual was developed to provide PsySR members around the world with a practical peace-building tool kit. The program highlights the dynamics common to prejudice and conflict along many dimensions -- race, class, culture, nationality, religion, and ethnicity. Education about these common dynamics relies upon a balance of teaching basic concepts, experiential learning, dialogue, and action. Brief sample talks are accompanied by overhead materials, followed by related experiential exercises. A second phase entails Dialogue Groups, and the third phase involves a joint project developed and implemented by participants from the diverse groups.

\section{9/11: Another Global Conflict Paradigm Shift}

The World Trade Center attack heralded a new East/West conflict-between Western imperialism and Islamic extremism. Revisions of the Enemy Images and the US \& THEM Manuals were necessitated by this seismic change in worldwide conflict.

The second edition of the Enemy Images Manual. In 2004, the Enemy Images program was updated in order to make its focus on international enmification applicable to the post 9/11 world. This new PsySR manual is titled Enemy Images: A Resource Manual on Reducing Enmity. It is described in greater detail in the next section.

The second edition of the US \& THEM Manual. The amalgam of religious, class, national and ethnic tensions reflected in this new world crisis highlighted by the events of 9/11 was readily addressed by US \& THEM program concepts and exercises (Fabick, 2002). Volkan (2004) states, "Ethnicity....incorporates religion as well as language; connected with shared images of the group's history, it establishes an especially sharp sense of "us" and "them."' So in response to 9/11, US \& THEM: Moderating Group Conflict was produced (Fabick, 2004).

The program was cited as a resource in the American Psychological Association's (APA) Task Force on the Psychological Effects of Efforts to Prevent Terrorism report (Kimmel, 2005). The relevance of the US \& THEM program in the reduction of community prejudice and conflict, and therefore a step in terrorism risk reduction, is described in a variety of recent volumes (Fabick, 2004; Fabick, 2006; Fabick, 2006).

\section{Description of the Enemy Images Project}

As described earlier, there are two editions of the Enemy Images Manual. The first, Dismantling the Mask of Enmity: An Educational Resource Manual on the Psychology of Enemy Images was written in 1989 and Enemy Images: A Resource manual on Reducing Enmity in 2004. Though the first focuses on superpower conflict during the Cold War and the second the new East/West conflict of Western Materialism and Imperialism vs. Islamic Extremism and Terrorism, there is great overlap between the two editions. Accordingly, the common elements of those editions will be outlined in this description of the Enemy Images project.

Enemy images may be pictorial as in political cartoons and war posters, or verbal as in slogans, e.g. "the only good commie is a dead one", extremist rhetoric, and propaganda. The project is focused on moderating enemy images through education on the psychology of enemy images, 
engaging program participants in experiential learning about their biases toward enemies, and increasing awareness of and resistance to the harmful effects of enemy images.

Presentations on enemy images may have a variety of related goals. The presenter may wish to reduce misconceptions between particular groups predisposed to conflict, increase critical thinking skills and resistance to propaganda, increase receptiveness to negotiation and conflict resolution, and build empathy skills.

The manuals begin with a section on the challenge of rethinking enmity considering current international relations. Following sections clarify the cognitive processes involved in such enmification, and challenge the belief in war as intrinsic to human nature. Both manuals rely upon research that illustrates how various psychological processes contribute to the exaggeration of an adversary's potential threat and negative qualities. Then examples from history and the mass media dramatize how those segments of society both reflect and further promote such enemy imaging. The section on the role of film in spreading such images is especially appealing to high school and college students.

Both editions of the Enemy Images project contain a number of exercises designed to engage participants. Furthermore, the experiential aspect of the project is intended to spark some change in perspective of the participants. Both Enemy Images Manuals provide a sample talk that can be used in combination with the other sections of the manuals in preparing class lectures or a community presentation. They include a section on ways to moderate the tendency to resort to such enmification.

\section{Description of the US \& THEM Program}

The purpose of both editions of the US \& THEM program is to moderate intergroup prejudice and conflict. So the following description of the program applies to each edition of it, i.e. US \& THEM: The Challenge of Diversity and US \& THEM: Moderating Group Conflict. The US \& THEM program is designed to highlight the dynamics common to prejudice and conflict along many dimensions, for example race, class, culture, nationality, religion, and ethnicity. Furthermore, education about these common dynamics in the workshop relies upon a balance of teaching basic concepts, experiential learning through structured activities, and post-workshop dialogue and action.

US \& THEM refers to the polarization of two or more groups. Such divisiveness is fueled by an exaggerated sense of one's own group as special and good. Accordingly, other groups are devalued and feared. The universal tendency to identify with our group and counter identify with other groups has to do with issues of identity, comfort and survival. Group boundaries exist to give cohesiveness to groups and to exclude disavowed parts of group members. They tend to provide order and prevent fusion within a large, chaotic world. Group identity tends to confer some sense of belonging, goodness, and worth.

US \& THEM thinking is magnified at times of intergroup conflict of interests, such as intensified economic competition, religious conflict or territorial dispute. And though prejudice and conflict have important historical, economic, and political causes, this program focuses on how such tensions are fueled psychologically-and how they can be moderated. 
US \& THEM workshops are structured to optimize the possibility of prejudice and conflict reduction as identified by research by group contact theory, called the Contact Hypothesis (Pettigrew, 1998). A sense of equality among participating group members is fostered by: balancing pre-workshop contact with group representatives; egalitarian seating arrangements in the workshop; balancing the number of participants from involved groups; striving for approximately equal status of each group's participants; using presenters who are not from participating groups, or equally representative of them. Presenters model respect for all participants, as well as for healthy diversity.

Workshop presenters facilitate participants' common goals by: emphasizing the superordinate goal of reduction of intergroup misunderstanding and tension; encouraging participants to engage in a collaborative process to achieve such outcome goals, e.g. introspection of their own attitudes, education about the other group members' experiences to enhance empathy with them, and exercises and follow-up activities designed to create greater connection with participants from the other group(s). Group interdependence is highlighted and valued.

Presenters establish a forum for participants to get to know "them" as individuals through the exploration of common interests, experiences, and aspirations; socialization opportunities; and structured dialogue and exercises designed to increase participants' empathic understanding of "them". Such personal contact with outgroup members promotes recategorization and crosscategorization (Urban and Miller, 1998) and decategorization (Wilder, 1986), thus allowing a more three-dimensional and empathic image of outgroup individuals.

Presenters seek the endorsement of participating group's community leaders. In some communities, it is not advisable to implement the program until tensions decline. If resources permit, holding the program outside the region may provide the psychological space and security conducive to open participation.

\section{Challenges in Using the Manuals}

There are a number of challenges that my colleagues and I, as well as others, have faced in the use of the Enemy Images and US \& THEM programs. Many times we have felt like we are "preaching to the choir." Quite frequently our presentations have been to other behavioral scientists. Frequently, audiences have been comprised of peace and justice activists. We have had less success in accessing groups with little exposure to psychological sophistication. More importantly, we have not often addressed groups in some degree of conflict. Nor have we often had in our audiences policymakers, either in the United States or abroad. In Working for Peace (2006), MacNair and Wollman state, "If you've gotten tired of merely preaching to the choir and would like to get out and help make social change...remember that choir has to be well organized and know what it's talking about (p.1)." I have found some comfort in that knowledge, but still strive to reach a broader audience.

Related to the problem of accessing those other target audiences is the problem of limited resources. Many of those who have obtained the manuals described in this article have been peace and justice activists. They have had scarce money, time, and institutional support to promote and present Enemy Images and US \& THEM workshops. Additionally, many of them have not been able to come to the American Psychological Association annual meetings for 
additional training in the use of the Manuals and have to rely upon the instructions in them alone, or accessing me by phone or email when a question arises.

Unlike the Enemy Images project which is typically used for presentations varying in length of one to several hours (all at once or in teaching/experiential modules), the US \& THEM Programs were designed to be more intensive. That has been a challenge in that the three phase US \& THEM program has usually not involved the second and third phases of the program. Most interested groups have only been interested in a presentation or workshop, i.e. the first phase of the program. The second and third phases were designed as part of the program because of the need for more than one exposure to new ideas and even experiences (in the experiential exercises of phase one). So the several session discussion groups between members of the different groups (phase two) and a collaborative action project between the different groups (phase three) were included given the challenges inherent in effecting lasting attitudinal and behavioral change. Additionally, the first phase of the US \& THEM programs is designed to be a one or two day workshop, but most groups have wanted a two to four hour workshop instead, given the priorities and pace of modern life.

Nonetheless, the Programs have been adopted by some influential organizations and used in some trouble spots in the world. For example, US \& THEM: The Challenge of Diversity is listed in Bridging the Racial Divide: A Report on Interracial Dialogue in America and in Interracial Dialogue Groups Across America: A Directory by the Center for Living Democracy. It was also included in President Clinton's Initiative on Race: Promising Practices website and that administration's Initiatives on Race Resources Desk Reference. The Center for Living Democracy identified US \& THEM: The Challenge of Diversity as one of the "top 22 programs in the country promoting racial and ethnic dialogue". Copies of the US \& THEM Presenter's Manual have been used in a variety of settings around the world, including Sarajevo, Chechnya, and South Africa. Furthermore, many college instructors have used portions of the Enemy Images and US \& THEM Manuals in their classes on conflict resolution, multicultural studies, social psychology, etc.

The four manuals may be obtained through Psychologists for Social Responsibility (208 "I" Street, NE, Washington, D.C., 20002). And the four manuals can also be downloaded at no cost from the organization's website (www.psysr.org).

\section{Sponsoring Organization:}

Psychologists for Social Responsibility (PsySR) is a U.S.-based, non-profit, international network of psychologists who draw upon the research, knowledge, and practice of psychology to promote durable peace at community, national and international levels. With members in 47 states of the USA and 39 other countries, PsySR is building a cross-cultural network to facilitate communication about the complex and multi-disciplinary problems of fostering cultures of peace.

Stephen D. Fabick, Ed.D.

Licensed Psychologist

Birmingham, Michigan USA

email: stevefabick@aol.com 


\section{References}

Bronfenbrenner, U. (1961). The mirror image in Soviet - American relations: A social psychologist's report. Journal of Social Issues, 17, 45-56.

Fabick, S. (1996). US \& THEM: The Challenge of Diversity. The Manual can be downloaded at www.psysr.org.

Fabick, S. (2002). US \& THEM: Reducing the risk of terrorism. In C. Stout (Ed.) The Psychology of Terrorism, Vol. 2, 225-241. Westport, CT: Praeger.

Fabick, S. (2004). US \& THEM: Moderating Group Conflict. The Manual can be downloaded at www.psysr.org.

Fabick, S. (Ed.) and Psychologists for Social Responsibility. (2004). Enemy Images: A Resource Manual on Reducing Enmity. The Manual can be downloaded at www.psysr.org.

Fabick, S. (2006). Beyond US \& THEM. In M. Fitzduff and C. Stout (Eds.) The Psychology of Resolving Global Conflict: From War to Peace. Westport, CT: Praeger.

Fabick, S. (2006). US \& THEM: Moderating Group Conflict--A Track Four Diplomacy Program. In P. Kimmel and C. Stout (Eds.) Collateral Damage: How the U.S. War on Terrorism is Harming American Mental Health. Westport, CT: Praeger.

Group for the Advancement of Psychiatry (1987). Us and Them: The Psychology of Ethnonationalism. New York: Bruner/Mazel.

Holt, R. and Silverstein, B. (Eds.) (1989). The Image of the Enemy: U.S. Views of the Soviet Union. Journal of Social Issues. 45, (2).

Hunt, Morton. (1991). The Compassionate Beast: Scientific Inquiry Into Altruism. New York: Wm Morrow and Company.

Itzkowitz,N. and Volkan, V. The demonization of the other. Unpublished paper.

Kats, R. (1982). Concerns of the Israeli: change and stability from 1962 to 1975. Human Relations, 35, pages 83-100.

Kimmel, P. (2005). Report of the Task Force on the Psychological Effects of Efforts to Prevent Terrorism, American Psychological Association. 
MacNair, R. (Ed.) and Psychologists for Social Responsibility (2006). Working for Peace. Atascadero, CA: Impact Publishers.

Middents, G. (1990). Psychological Perspectives on Enemy-Making. Organization Development Journal. Summer, 44-48.

Oskamp, S. (1965). Attitudes toward U.S. and Russian Actions-A double standard. Psychological Reports, 16, 43-46.

Pettigrew, T. (1998). Intergroup contact theory. Annual Review of Psychology, 49, 65-85.

Psychologists for Social Responsibility (1989). Dismantling the Mask of Enmity: An Educational Resource Manual on the Psychology of Enemy Images. Selfpublished by PsySR and available at www.psysr.org.

Rieber, R. and Kelley, R. (1991). Substance and shadow: Images of the enemy. In R. Rieber (Ed.) The Psychology of War and Peace. 3-38. New York: Plenum Press.

Sande, G.N., Goethals, G.R., Ferrari, L. \& Worth, L.T. (1989). Value-guided attributions: Maintaining the moral self-image and the diabolical enemy image. Journal of Social Issues, 45 (2), 91-118.

Silverstein, B. (1989). Enemy images: the psychology of U.S. attitudes and cognitions regarding the Soviet Union. American Psychologist, 44, 903-913.

Silverstein, B. \& Flamenbaum, C. (1989). Biases in the perception and cognition of the actions of enemies. Journal of Social Issues, 45 (2), 51-72.

Stein, H.F. (1980). Culture and ethnicity as group-fantasies: a psychohistory paradigm of group identity. The Journal of Psychohistory, 9(1), 21-51.

Taylor, D.M. \& Jaggi, V. (1974). Ethnocentrisms and causal attribution in a South Indian context. Journal of Cross-Cultural Psychology, 5 (2), 152-171.

Urban, L. \& Miller, N. (1998). A theoretical analysis of crossed categorization effects: A meta-analysis. Journal of Personality and Social Psychoogy, 74, 894-908.

Volkan, V. (1988). The Need to Have Enemies and Allies: From Clinical Practice to International Relationships. Northvale, NJ : Jason Aronson.

Volkan, V. (2004). Blind Trust: Large Groups and Their Leaders in Times of Crisis and Terror. Charlottesville, VA: Pitchstone Publishing. 
Wilder, D. (1986). Social categorization: Implications for creation and reduction of intergroup bias. In L. Berkowitz (Ed.) Advances in Experimental Social Psychology, 19, 291-355, Orlando, FL: Academic Press. 